\author{
Abstracta Iranica \\ Abstracta Iranica Revue bibliographique pour le domaine irano-aryen \\ Volume 37-38-39 | 2018 \\ Comptes rendus des publications de 2014-2016
}

\title{
Agnese Fusaro. « From Ceramics to History. Pottery Contribution to the History of Ghazni »
}

Sandra Aube

\section{OpenEdition \\ Journals}

Édition électronique

URL : http://journals.openedition.org/abstractairanica/42584

DOI : 10.4000/abstractairanica.42584

ISBN : 1961-960X

ISSN : 1961-960X

Éditeur :

CNRS (UMR 7528 Mondes iraniens et indiens), Éditions de l'IFRI

Référence électronique

Sandra Aube, « Agnese Fusaro. «From Ceramics to History. Pottery Contribution to the History of

Ghazni » », Abstracta Iranica [En ligne], Volume 37-38-39 | 2018, document 2, mis en ligne le 10 mars 2018, consulté le 02 octobre 2020. URL : http://journals.openedition.org/abstractairanica/42584

DOI : https://doi.org/10.4000/abstractairanica.42584

Ce document a été généré automatiquement le 2 octobre 2020.

Tous droits réservés 


\title{
Agnese Fusaro. « From Ceramics to History. Pottery Contribution to the History of Ghazni »
}

\author{
Sandra Aube
}

\section{RÉFÉRENCE}

Agnese Fusaro. « From Ceramics to History. Pottery Contribution to the History of Ghazni », Eurasian Studies 13 (2015), p. 5-22.

1 Le volume 13 de la revue Eurasian Studies réunit quatre articles résultant d'un panel sur le site de Ghazni (Afghanistan), donné à l'occasion du "Symposia Iranica - First Biennial Iranian Studies Graduate Conference" à l'université de St Andrews (avril 2013). Capitale ghaznévide (977-1186), puis ghoride, occupée dès la période bouddhique et jusqu'aux temps modernes, Ghazni avait fait l'objet d'investigations archéologiques entre 1957 et 1978 par la Mission Archéologique Italienne en Afghanistan. Depuis lors, l'accès au site est cependant devenu extrêmement limité. En s'appuyant sur les archives photographiques et sur le matériel collecté au cours de ces anciennes campagnes, Agnese Fusaro, Viola Allegranzi, Valentina Laviola et Martina Massullo, toutes membres du projet «Islamic Ghazni. An IsIAO Archaeological Project in Afghanistan » dirigé par Roberta Giunta (IsIAO/ «L'Orientale », 2004-), offrent des données nouvelles et très attendues sur l'histoire de ce site d'envergure.

2 Agnese Fusaro signe le premier article de cette série, qui émane des recherches de doctorat qu'elle a menées à la Sapienza Universtà de Rome (thèse défendue en 2014). À travers un important corpus de céramiques collectées sur le site de Ghazni, lors des fouilles effectuées jadis sur le palais royal et dans la "Maison des lustres ", Fusaro propose ici un nouveau référent typologique. Elle décrit les évolutions de cette céramique entre les $\mathrm{X}^{\mathrm{e}}$ et $\mathrm{XVII}^{\mathrm{e}}$ siècles à travers quatre grandes phases principales ; l'auteur signale également les importations (cf. notamment les lustres importés d'Iran 
ou d'Asie centrale, les porcelaines d'Extrême-Orient, etc.). Conjuguée aux données archéologiques, son étude propose notamment des chronologies relatives pour certaines structures, et permet d'identifier différentes phases de construction et d'occupation pour le palais et la « Maison des lustres».

\section{AUTEURS}

\section{SANDRA AUBE}

CNRS, Mondes iranien et indien, Paris 